\title{
Fluent in the Simulation of the Application of the Natural Gas Leakage
}

\author{
Xuegang- LI \\ Hebei United University \\ Tangshan, China \\ 2357769870@qq.com
}

\author{
Hongchao -JI \\ Hebei United University \\ Tangshan, China \\ jihongchao666@163.com
}

\author{
Yaogang -LI \\ Hebei United University \\ Tangshan, China \\ jxlyg@heuu.com.cn
}

\begin{abstract}
Fluent is used for simulation calculation fluid flow and component transport and chemical reaction CFD general software, are widely used in engineering field and scientific research. Introduces the basic characteristics of fluent software, the application of fluid mechanics theory and method, this paper analyzes the gas field engineering problems to solve the basic algorithm model, and with natural gas leakage, for example, by using the software to simulate the natural gas leakage phenomenon of diffusion.
\end{abstract}

\section{Keywords- Fluent simulation Gas leakage}

\section{INTRODUCTION}

Petroleum industrial production processes involve dangerous gas is mainly gas. In the oil exploration and production, oil drilling construction process, logging construction process, the downhole operation process, the production process, natural gas production process and oil and gas gathering and transferring process, there is the risk of gas leakage diffusion. Natural gas for flammable and explosive, poisonous and harmful mixture, once leakage diffusion, is caused extremely easily explosion combustion accident or blowout out of control accident, caused the personnel, poison death and environmental pollution. If after the accident blind evacuation or delay evacuation, the casualties more and more large range of harm. For gas pipeline leakage diffusion numerical simulation can rapidly predict gas after the leakage diffusion scope and dangerous range, for policy makers timely and efficiently evacuate residents and take the appropriate rescue measures provide scientific guidance ${ }^{[1.2]}$.

\section{THE THEORETICAL ANALYSIS}

\section{A. material transmission model}

The gas diffusion flow problems often USES Reynolds time-averaged equation ${ }^{[3]}$.

$$
\begin{gathered}
\frac{\partial \bar{U}_{i}}{\partial x_{i}}=0 \\
\frac{\partial\left(\rho \bar{U}_{i}\right)}{\partial t}+\bar{U}_{j} \frac{\partial\left(\rho \bar{U}_{i}\right)}{\partial t_{j}}=\frac{\partial\left(\bar{\rho}_{i}\right)}{\partial x_{i}}+\frac{\partial\left[u \frac{\partial\left(\bar{U}_{i}\right)}{\partial j}-\rho{\overline{u_{i}^{\prime} u_{i}^{\prime}}}^{\prime}\right]}{\partial x_{i}}
\end{gathered}
$$

First author: xuegang-li, (1979 ), male, instructor, The main research direction of computer aided engineering, CAE/CAM
Type of second order related items--- $\rho \overline{u_{i}^{\prime} u_{i}^{\prime}}$ Also called the Reynolds stress and turbulent stress, on behalf of the fluctuating velocity on the influence of average flow. Due to the existence of the Reynolds stress, make equations become not closed. Calculation, the engineering application in a wider Bousinesq turbulence eddy viscosity coefficient model:

$$
-\rho \overline{u_{i}^{\prime} u_{i}^{\prime}}=u_{t}\left[\frac{\partial\left(\bar{U}_{i}\right)}{\partial x_{j}}+\frac{\partial\left(\bar{U}_{j}\right)}{\partial x_{i}}\right]-\frac{2}{3} \rho \kappa \sigma_{j}
$$

Type: $k$, ut were turbulent kinetic energy and turbulence viscosity coefficient, the value changes of empty at any time by turbulence model decision, take the turbulent kinetic energy and turbulent $\varepsilon$ can dissipation rate transmission equation, constitute $\kappa-\varepsilon$ the entire agreement between the parties process model. $\kappa-\varepsilon$ Model will and turbulence are linked when parameters, make equations closed.

The standard $\kappa-\varepsilon$ model is one and a half empirical model, this model hypothesis full development of turbulence, ignored the influence of molecular viscosity is the standard $\kappa-\varepsilon$ model applies only to completely turbulence.

\section{B. Substance diffusion model}

FLUENT through the species transmission diffusion conservation equation solution of predictable $I$ species quality content $r_{i}$, its species transmission diffusion equation is as follows ${ }^{[4]}$ :

$$
\frac{\partial}{\partial t}\left[\rho \gamma_{i}\right]+\nabla\left[\rho \overline{v \gamma_{i}}\right]=-\nabla \overline{J_{1}}+R_{i}+S_{i}
$$

Type: $R i$ for existing chemical reaction time chemical reactions produce species $I$ rate, no chemical reaction time can be ignored; Si for user defined and produce species rate; $J i$ for $I$ species quality diffusion rate.

$\mathrm{n}$ the turbulent flow through the following form of FLUENT solving quality diffusion:

$$
\overline{J_{1}}=\left[\rho D_{i, m}+\frac{u_{t}}{s_{c t}}\right]
$$

Type: Sct for turbulence schmidt number. 
The above is research component transport theory foundation, can be used to simulate all kinds of complicated combustion and all kinds of chemical reaction process.

\section{NUMERICAL MODELING}

\section{A. Geometric model and grid partition ${ }^{[5]}$}

This article chooses the pipe diameter is $610 \mathrm{~mm}$, the starting point of the pipeline pressure is $3.5 \mathrm{Mpa}$, terminal pressure $3.35 \mathrm{Mpa}$, natural gas, with an average annual throughput of $20 * 108$ design years working days $360 \mathrm{~d}$, external environment highest temperature 38 c, minimum - 10 c of natural gas, the average temperature for 26 c. Simulate the take a large enough and contains leakage area and diffusion area, space (100 m high, leakage radius is $50 \mathrm{~m}$ ), the natural gas in this space mainland diffusion phenomenon, leakage mouth with $2 \mathrm{~d}$ hole model, caliber to $10 \mathrm{~cm}$, the right level to the right of the wind speed for $5 \mathrm{~m} / \mathrm{s}$. Due to the relatively simple 2 d model, so choose Gambit model. High speed air leakage through the mouth jet out, in a certain height above the mouth leakage within the velocity gradient is bigger, therefore, it is necessary to introduce calculation regionalization into several pieces, and leakage mouth top of the areas that need to be grid refining, so will model is divided into three areas, specific upper shows.

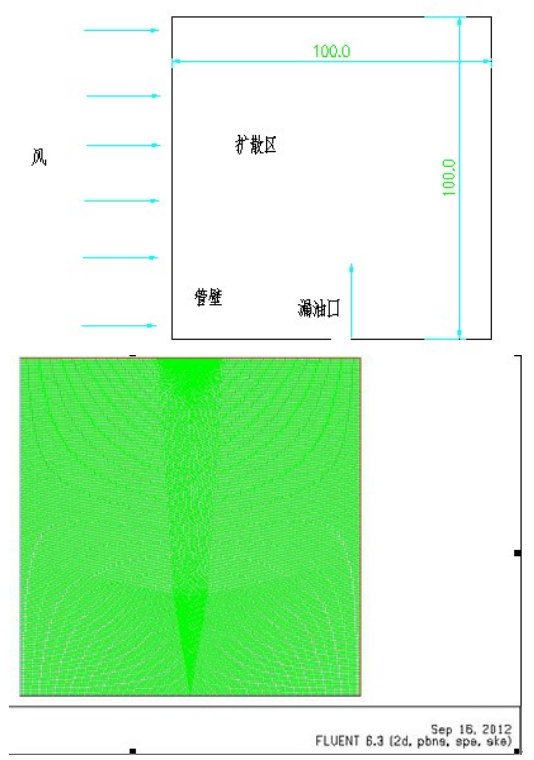

Figure 1. Geometric model and grid model

\section{B. Initialization setting boundary conditions}

This paper will leak mouth defined as speed import (VELOCITY_INLET) name is in, the left side will be defined as speed import (VELOCITY_INLET), the name is wind_in, will calculate the area the top three line and area of most the right side all defined as pressure exports (PRESSURE_OUTLET), its name out1 respectively, out2, out3, out4. Leakage mouth speed of $213.42 \mathrm{~m} / \mathrm{s}$, leakage mouth components concentration in the setting of $\mathrm{CH} 4$ is 0.935, the rest for $\mathrm{CO} 2$ and $\mathrm{H} 2 \mathrm{O}$, the boundary of the import in the wind in the set speed set to $5 \mathrm{~m} / \mathrm{s}$, component concentration all set to 0 .

\section{The calculation results and post-processing}

Figure 2 can see: stress nephogram shift to right, leakage the inlet pressure is bigger, leakage space internal pressure quickly reduce; With the increase of the horizontal distance, such as pressure surface slowly to the right to expand, visible gas to right diffusion increase. Can be seen from the figure 3 : in $20 \mathrm{~m}$ height less than can be approximately regarded as free diffusion flow, the wind to leak mouth nearby leakage situation the impact is not big, In the inlet wind leakage of momentum is far less than the leakage gas momentum, and when leakage rate reduced hours, the wind for gas leakage has a great influence, leading to the gas leakage clouds gathered more next wind direction, gas to reduce the height, and visual near the ground and place diffusion range increased to expand.

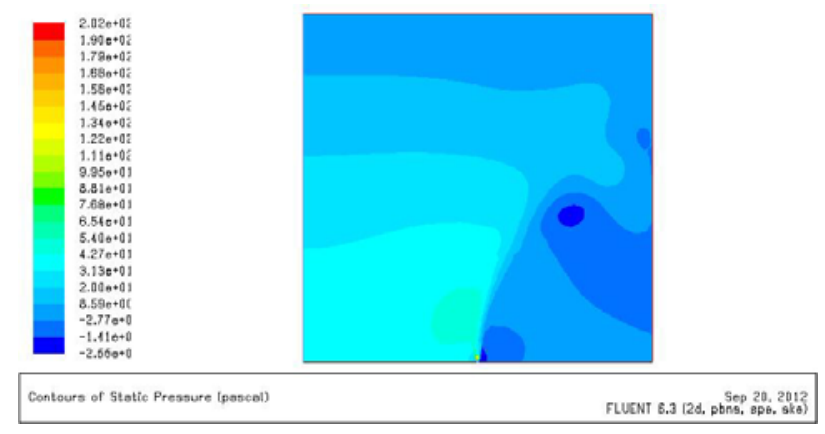

Figure 2. Stress nephogram

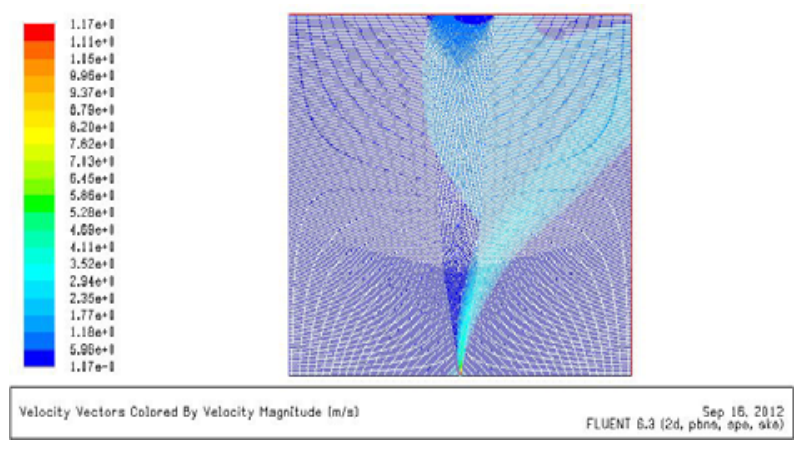

Figure 3. Speed nephogram

Because the concentration of $\mathrm{CO} 2$ in space beyond a certain range will pose a threat to human life, so by changing the cloud image display range, has clearly safety area, numerical simulation of the main purpose is to determine the gas leakage risk area. For flammable poisonous gas should not only consider the methane explosion range consider the harm of $\mathrm{CO} 2$. The volume fraction of methane explosion range is $50 \% \sim 50 \%$. $5 \mathrm{~m} / \mathrm{s}$ wind speed of the safety range distribution as shown in figure 6-7 shows.

In figure 6-7 in dark blue area for leakage safety area, shallow blue, green and yellow area for carbon dioxide and methane respectively the danger zone. The figure 7 visible: in $5 \mathrm{~m} / \mathrm{s}$ wind conditions. Danger zone in next wind gathered. This area if there are staff stay is affected by CO2 infestation. 
So in leakage accident occurs personnel should be first evacuated the area.

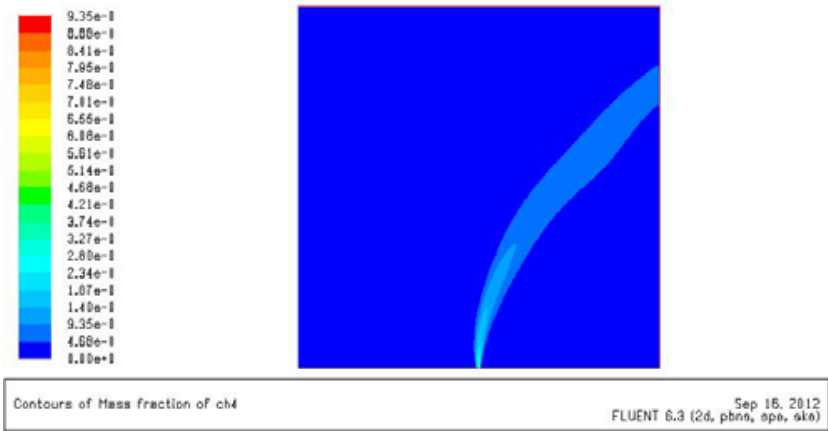

Figure 4. CH4 component concentration distribution nephogram

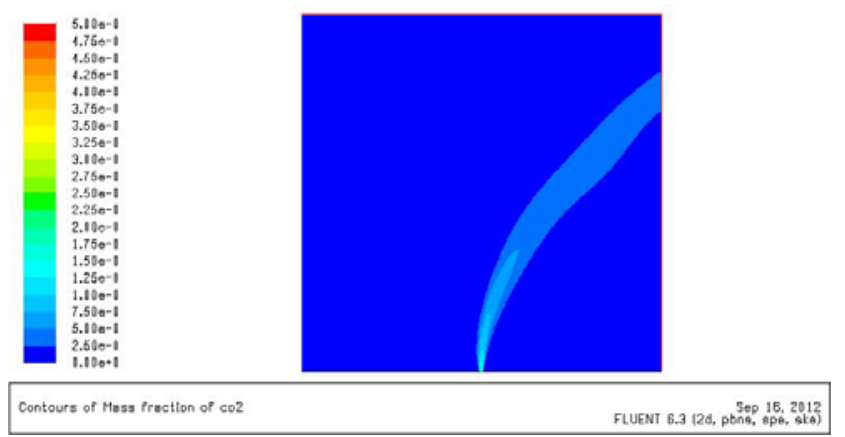

Figure 5. CO2 component concentration distribution nephogram

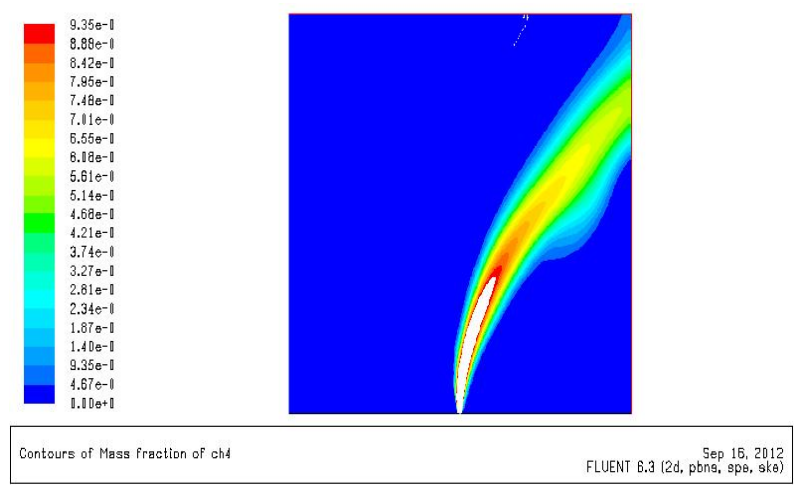

Figure 6. CH4 safety area

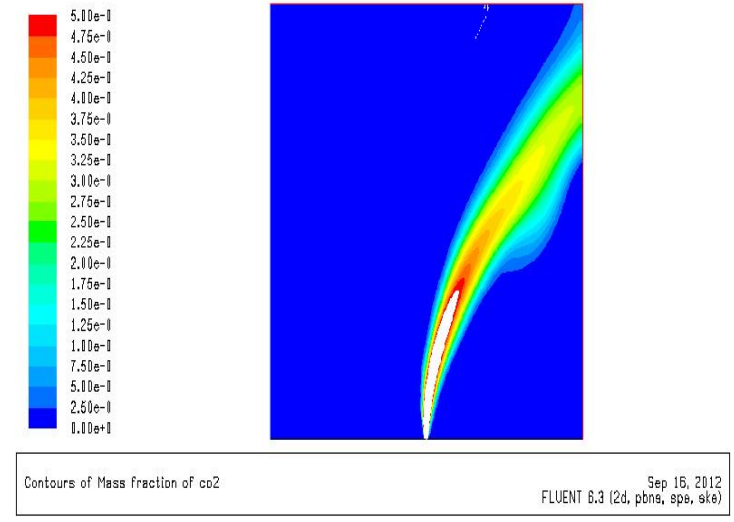

Figure 7. CO2 safety area

\section{CONCLUSION}

This paper introduces the software fluent and the component transport model application, analyzes the natural gas to solve the leakage of the algorithm model. Fluent software as a powerful CFD calculation software can conveniently flexible the problems on the analysis, calculation, professionals from multifarious programming work liberate, more effective to reduce the experimental work of the blindness and workload, have more time and energy to consider the essence of the problem, improve work efficiency. Specific for this paper get the conclusion:

(A) Using numerical simulation method for natural gas leakage was studied, and concludes that the risk of leakage area, and the experimental results were compared, fluent can very good simulation gas leakage.

( B ) A numerical model for natural gas leak test to provide reference and help. According to the specific test, the use of different wind speed and different concentration of natural gas simulation, can more scientific understanding of gas leakage process changes.

\section{REFERENCES}

[1] YAN Xiao- kang, WANG Li- jun. Application of Fluent in the Ventilation Engineering [J].coal mine machinery, 2005 (11) : 153155

[2] WANG Fujun. Computational fluid dynamics (CFD) analysis [M].beijing : Tsinghua university press, 2004.

[3] WANG Kai-nan, HOU Xian-jun, YAN Shao-jie. Study of Combustion Characteristics of Natural Gas Based on Fluent[J]. Automobile Science and Technology,2011(3)5:12-13

[4] S.Y.Liao , D.M.Jiang , Q.Cheng.Determination of laminar burningvelocities for natural gas [J] .Fuel, 83 (2004) 1247-1250.

[5] Fluent Inc. FLUENTUsers Guide[Z].Fluent Inc.,2003. 